\title{
THE RAUWOLFIA ALKALOIDS IN THE TREATMENT OF HYPERTENSION
}

\author{
BY \\ MAURICE MCGREGOR AND N. SEGEL
}

\begin{abstract}
From the Department of Medicine, University of the Witwatersrand, and Johannesburg General Hospital, and the Cardio-Pulmonary Research Unit, Council for Scientific and Industrial Research

Received November 12, 1954
\end{abstract}

Since the discovery of the hypotensive action of the alkaloids of Rauwolfia serpentina (Chopra, 1933) many reports have appeared dealing with the chemistry, pharmacology, and clinical use of these drugs in hypertension. It is still difficult, however, to give a clear idea as to their exact place in therapy. Many workers have reported extremely good results, with a hypotensive response in one-half to three-quarters of the subjects treated (Hughes et al., 1954; Arnold and Bock, 1953; Hensler, 1953; Vakil, 1953; Chakravarty, 1951) while other reports are more disappointing with a satisfactory response in only 33 per cent (Wilkins and Judson, 1953) and 8 per cent of subjects treated (Löffler, 1953). Nor is it clear from the reports what dosage should be employed. While Freis and Ari (1954) recommend a maintenance dose of $0 \cdot 2-0.5 \mathrm{mg}$. reserpine daily others have found this dose completely ineffective and have employed 4.0-6.0 mg. daily of the same substance (Douthwaite, 1954). In a trial designed to clarify these points we were soon impressed by the striking weight increase of most subjects while on rauwolfia and by the appearance of cardiac failure in some. We accordingly modified our procedure to include a study of the influence of this drug on heart output, pulse rate, and fluid balance. The results of these observations are reported below.

\section{MATERIAL AND METHOdS}

The subjects of this study were 19 ambulatory patients suffering from essential hypertension. Seven were considered to be severe, 6 moderate, and 6 mild in degree (Table I). The type and severity of the condition were assessed by means of clinical examination, retinoscopy, electrocardiography of the heart, examination for chemical and microscopic abnormalities and concentrating power of urine, and an estimate of blood non-protein nitrogen content. Intravenous pyelography was carried out in several cases. Papillœdema was a feature of Cases 4 and 6 only. There was radiological or electrocardiographic evidence of left ventricular hypertrophy in all but two subjects and five complained of some effort dyspnœa. The only evidence of renal impairment was a failure to concentrate urine above a specific gravity of 1015 in six cases.

Two drugs were employed in this study; an extract of the whole root of Rauwolfia serpentina* and reserpine, $\uparrow$ a pure crystalline alkaloid derived from this root. Both were taken 8-hourly by mouth. The nineteen subjects were each studied for a mean period of 47 weeks, every trial being divided into three periods. During the first period, which lasted for a mean of 17 weeks, a placebo was administered. During the second period which lasted for a mean of 21 weeks an active Rauwolfia preparation was given, and during the third period this was again replaced by a placebo, in most instances of identical appearance and taste: the average duration of this second placebo period was 11 weeks. In 7 subjects, as can be seen from the table, a complete second trial was carried out making a total of 26 trials in the 19 subjects.

$$
\text { * Raudixin, Squibb. }
$$

$391+$ Serpasil, Ciba. 
During the course of 16 trials repeated ballistocardiograms * were recorded on an average of 4.7 times while on placebo and 4.7 times while on a Rauwolfia drug in each trial, cardiac outputs being calculated according to the method of Tanner (1939). Although these records were not made under ideal basal conditions each patient was tested at the same time of day by the same observer after twenty minutes rest on the table.

Throughout the period of study each subject was seen by the same observer in the same room at the same time of day at weekly or fortnightly intervals. A supine blood pressure was recorded as soon as the subject lay down and again after five minutes rest, that reading, with the lower diastolic pressure, being used for the purposes of comparison in this study. Thereafter a standing blood pressure was recorded and symptomatic changes noted down. In Table I all the pressures while on placebo, both before and after the period on active drug, are averaged and compared to the average of all readings obtained during the period on rauwolfia. Because the effect of rauwolfia may be slow to appear and may continue for some time after the drug is withdrawn (Joiner and Kauntze, 1954), the blood pressures recorded for three weeks after the institution or cessation of rauwolfia treatment have not been included in this comparison.

\section{RESULTS}

It is clear that the average blood pressure on treatment was considerably lower than the average control readings in 23 of the 26 trials, or in 16 of the 19 subjects. Comparison of the means in each individual trial by Student's t test showed that there was a statistically significant fall of the systolic pressure in 18, of diastolic in 21, and of both systolic and diastolic in 17 trials ( $p=0.05$ or less) (Yule and Kendall, 1940). Moreover, the graphed results in each case showed that the lowest falls were often only obtained towards the end of the rauwolfia period at which time pressures were normal or near normal (less than 170/95) in 5 of the 13 severe and moderate cases and in 5 of the 6 mild cases. Postural hypotension was not observed.

No symptomatic improvement occurred that could definitely be ascribed to rauwolfia in this study. Symptoms possibly related to hypertension were present in 11 of the 19 subjects. Headache (7 cases) invariably improved on placebo and no further improvement was noted on rauwolfia. Angina (4 cases) was unaffected in 3 and was possibly worse in one. Dyspnœa, almost certainly of psychogenic origin was completely relieved by placebo and coincident psychotherapy in one case. In 3 patients it was aggravated and in 2 somewhat relieved during therapy.

Side effects appeared at widely different dosage levels. Some subjects were extremely uncomfortable on $0.75 \mathrm{mg}$. reserpine daily while one subject felt no symptoms on $6.0 \mathrm{mg}$. daily for a period of two months. They were reported in 10 subjects and although not dangerous they were sufficiently severe to limit the usefulness of the drug in 5 of these. The commonest symptoms were tiredness, sleepiness, depression, nasal obstruction and breathlessness. Most of these subjects "felt awful" on rauwolfia and felt, by contrast, extremely well when rauwolfia was replaced by placebo (in many cases identical in appearance and taste). In no case was there euphoria or a sense of well being observed which was not also obtainable with placebo. The rarer symptoms were insomnia ( 1 case), diarrhœa ( 1 case), nocturnal frequency ( 3 cases), increased appetite ( 1 case), increased thirst ( 2 cases) and disturbance of vision ( 1 case).

In addition to these subjective side effects a gain in weight was observed in 10 subjects during treatment and a steady weight loss due to dieting was temporarily arrested in a further two (Fig. 1) while the temporary appearance of œdema and a raised venous pressure in five led to the diagnosis of congestive cardiac failure.

There was no observable difference in the hypotensive action or side effects of raudixin and serpasil except in Case 19 . In this subject $0.5 \mathrm{mg}$. serpasil produced shakiness and weakness of an intolerable degree with aggravation of angina, whereas $750 \mathrm{mg}$. raudixin daily produced no effects

\footnotetext{
* High-frequency resisted ballistocardiograph (Starr et al., 1939).
} 

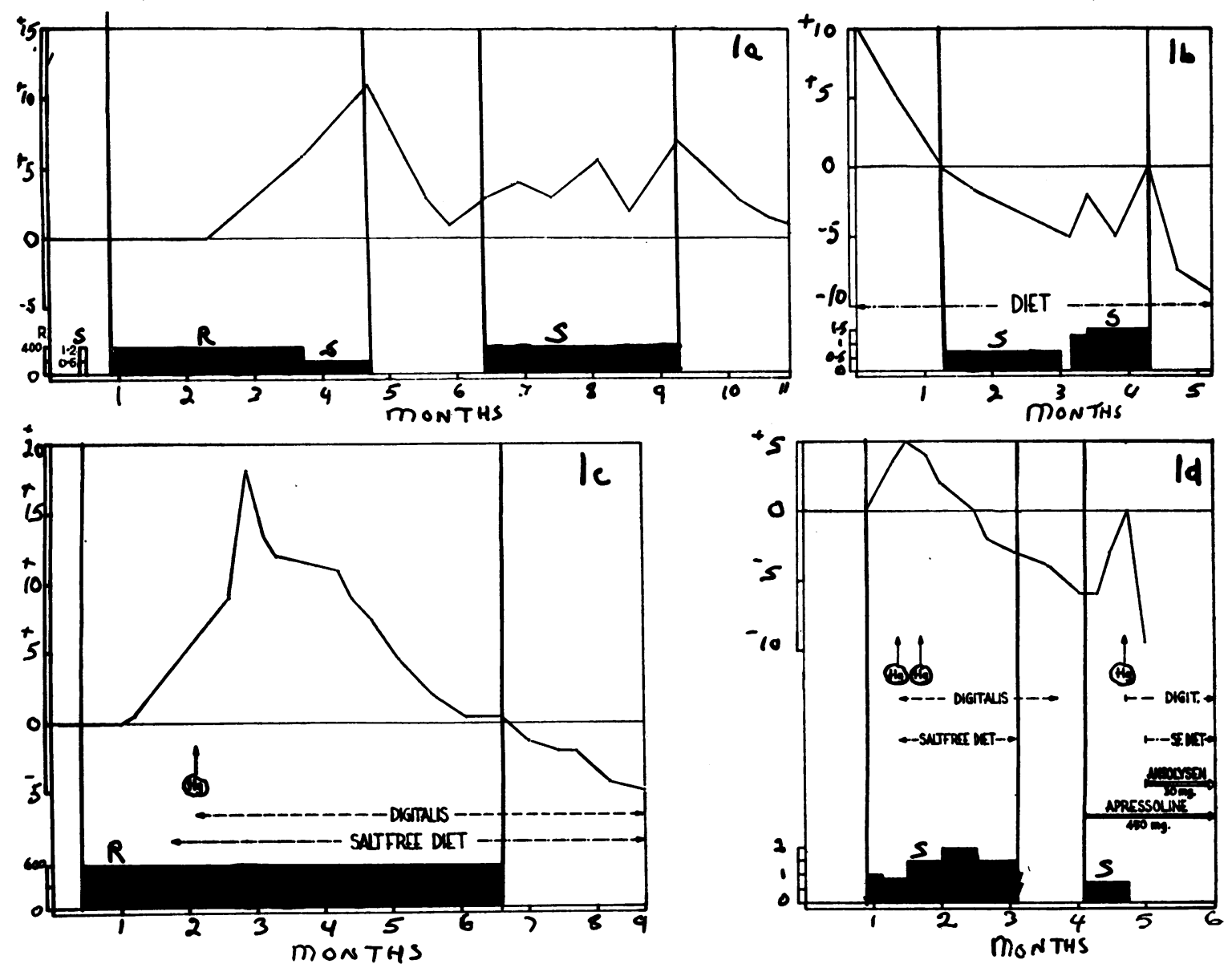

Fig. 1.-Illustrating weight changes in four cases while on Rauwolfia drugs. $\mathbf{R}=$ raudixin-total daily dose in mg. $\mathrm{S}=$ serpasil—total daily dose in $\mathrm{mg}$. $\mathbf{H g}=$ Mercurial diuretic.

GraPH 1a. (Case 1). Note the rise in weight while on raudixin and serpasil in both trials and drop on withdral.

GRAPH 1b (Case 6). Note the temporary rise in weight when serpasil dose increased, and sudden drop on withdrawal. Reducing diet throughout.

GRAPH 1c (Case 2). Note marked weight gain on serpasil and rapid loss after institution of digitalis and salt-free diet.

GRAPH 1d (Case 7). Note the weight gain on serpasil and then weight loss with digitalis, mercury and salt-free diet in first trial. In second trial there is a rapid fall in weight following a single injection of mercury and withdrawal of serpasil.

whatever apart from a substantial lowering of blood pressure. The unpleasant effects of serpasil were abolished when this drug was replaced by placebo.

Observations of pulse rate and cardiac output were made during 16 trials. As in the case of blood pressure measurements the average of all readings obtained while under the influence of rauwolfia was compared to the average of all readings obtained while on placebo (Table I). Therapy resulted in a bradycardia in 14 trials with a corresponding increase in stroke volume and (within the errors of the method) a constant cardiac output in 12 of these. In two trials, however (Case 1, trial 2 and Case 19), there was an apparently significant fall in the resting cardiac output while on rauwolfia and in two others (Cases 3 and 5) the drug appears to have had no significant effect on these measurements. 


\section{Discussion}

The results reported above confirm the almost universal view that a substantial reduction in blood pressure can be obtained by the administration of rauwolfia in many cases of essential hypertension. A worthwhile reduction of blood pressure was obtained in 16 of our 19 subjects while on treatment. That this was the result of the drug was borne out by the fact that pressures rose again within a month of withdrawal of rauwolfia in each case and in the 6 responsive subjects who received a second trial pressures were again lowered while on the drug. Moreover our results, so far as they go, confirm the conclusions of Moyer (1954) that rauwolfia is equally effective in both mild and severe cases. Like other workers (Wilkins, 1954; Hughes et al., 1954) we found no difference in the therapeutic effectiveness or the incidence of side effects between the extract of whole root and the pure alkaloid except in the one subject who could only tolerate the former.

As may be seen from Table I, it is clearly not possible to lay down optimal dosage levels within any narrow limits. There was great variability from patient to patient both in the quantity of rauwolfia required to reduce the blood pressure and in the quantity tolerated before side effects became too severe. Nor was there any evidence of a constant toxic therapeutic ratio. While in some, normal pressures could be obtained with as little as $150 \mathrm{mg}$. raudixin or $0.8 \mathrm{mg}$. serpasil daily, others required as much as $6 \mathrm{mg}$. serpasil daily to achieve this result. The dose used, therefore, is frequently the result of a compromise in which the desirability of attaining a normal pressure must be balanced against the extent of incapacity due to side effects.

Of special interest was the occurrence of an increase in weight in some subjects while on rauwolfia. It has been well known for some years and has been attributed by some to an increase in appetite (Hughes et al., 1954; Ford and Moyer, 1953). That this was the only cause for the increase in weight seemed to us unlikely for several reasons. Firstly, only two of our subjects reported an increase in appetite, even on direct questioning. Secondly, the rapidity with which weight was gained on treatment and lost again thereafter seemed unlikely to be the result of increased nutrition alone (Fig. 1, a, b, and d). Thirdly, there was evidence in five cases of fluid retention in the form of raised venous pressure and ankle œdema (Table I) which could be readily abolished in each case by the administration of mercurial injections and a low salt diet. Finally, it is apparent that in some cases the administration of digitalis, mercurials, and a low salt diet obviously arrested, or actually reversed, the weight increase in those subjects in whom it was employed (Fig. 1, c and d). These observations in some of the earlier cases immediately suggested the possibility that the weight increase on rauwolfia might be due to heart failure and it was with this possibility in mind that subsequent cases were studied in greater detail.

Dyspnœa may be difficult to assess in individuals receiving rauwolfia drugs. Nasal obstruction may cause discomfort which is easily confused with respiratory dyspnœa and according to Winsor $(1953,1954)$ may even produce attacks similar to paroxysmal nocturnal dyspnœa in subjects receiving an evening dose. It was our opinion, however, that the dyspnœa reported in our cases was not solely the result of nasal obstruction. In each, the cardiac status was such as to make heart failure a distinct possibility. In none had there been any evidence of heart failure at the commencement of rauwolfia therapy and in all except Case 10 signs and symptoms of failure did not recur at its conclusion even when digitalis, mercury and low salt diet were discontinued. We concluded that a syndrome that was almost certainly due to heart failure had developed in 6 of our 19 cases while on rauwolfia treatment and that it had cleared up when this drug was withdrawn in 5 cases.

The mechanism whereby rauwolfia caused this temporary heart failure during its administration is not known. It has previously been shown in acute experiments in dogs and in man (Moyer, 1954; Moyer et al., 1954; Sellers and Hafkenschiel, 1954) that the intravenous infusion of reserpine has no significant effect on cardiac output. In view of the fact that there seem to be several differences between the actions of rauwolfia in acute and long-term experiments it was thought that a study of output carried on over months might produce a different result. As can be seen from 
TABLE I

Influence of Rauwolfia Alkaloids on Blood Pressure, Circulation, and Fluid Balance

\begin{tabular}{|c|c|c|c|c|c|c|c|c|c|c|c|c|c|c|c|c|c|c|c|}
\hline Uू & ひ & 变 & 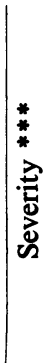 & 㞼 & 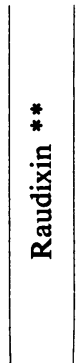 & 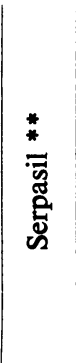 & 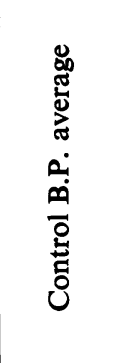 & 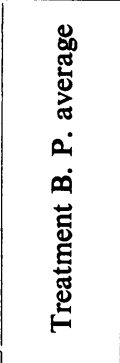 & 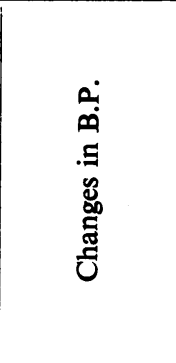 & 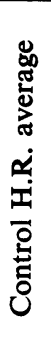 & 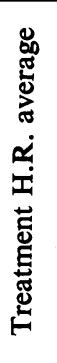 & 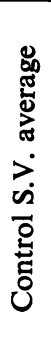 & 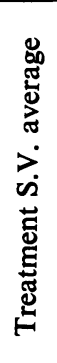 & 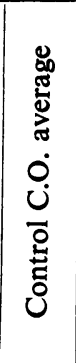 & 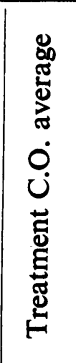 & 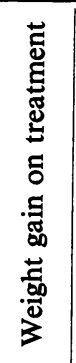 & 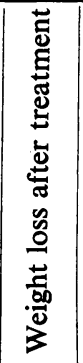 & 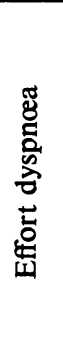 & $\frac{\pi}{\tilde{E}}$ \\
\hline \multirow[t]{2}{*}{1} & \multirow[t]{2}{*}{$\mathbf{M}$} & \multirow[t]{2}{*}{40} & \multirow[t]{2}{*}{3} & 1 & 400 & & $228 / 148$ & $184 / 108$ & $-44^{*} /-40^{*}$ & 70 & 60 & 44 & 59 & $3 \cdot 14$ & 3.54 & +11 & -8 & & \\
\hline & & & & 2 & & $1 \cdot 2$ & $220 / 152$ & $190 / 125$ & $-30^{*} /-27^{*}$ & 78 & 60 & 49 & 36 & 3.53 & $2 \cdot 13$ & +4 & $\overline{-6}$ & + & \\
\hline \multirow[t]{2}{*}{2} & \multirow[t]{2}{*}{$F$} & \multirow[t]{2}{*}{39} & \multirow[t]{2}{*}{3} & 1 & 600 & & $254 / 144$ & $189 / 112$ & $-65^{*} /-32^{*}$ & 76 & 60 & 64 & 74 & 4.90 & 4.45 & +17 & -4 & + & + \\
\hline & & & & 2 & & $2 \cdot 0$ & $271 / 132$ & $175 / 104$ & $-96^{*} /-28^{*}$ & 77 & 54 & 57 & 78 & $4 \cdot 27$ & 4.02 & -2 & -1 & & \\
\hline \multirow[t]{2}{*}{3} & \multirow[t]{2}{*}{ F } & \multirow[t]{2}{*}{40} & \multirow[t]{2}{*}{2} & 1 & 300 & & $193 / 127$ & $139 / 96$ & $-54^{*} /-31^{*}$ & & & & & & & 0 & 0 & & \\
\hline & & & & 2 & & $2 \cdot 0$ & $184 / 125$ & $152 / 101$ & $-32 * /-24$ & 76 & 76 & 54 & 44 & $3 \cdot 60$ & $3 \cdot 34$ & 0 & 0 & & \\
\hline 4 & F & 63 & 1 & 1 & 300 & & $196 / 103$ & $160 / 81$ & $-36 * /-22^{*}$ & & & & & & & +3 & 0 & & \\
\hline 5 & $\mathbf{F}$ & 51 & 1 & 1 & 800 & & $198 / 124$ & $183 / 100$ & $-15^{*} /-24^{*}$ & 72 & 70 & 62 & 59 & $4 \cdot 72$ & $4 \cdot 15$ & +12 & -3 & & \\
\hline 6 & F & 41 & 1 & 1 & & 1.5 & $191 / 127$ & $133 / 81$ & $-58^{*} /-46^{*}$ & 81 & 59 & 62 & 77 & $4 \cdot 11$ & 4.46 & +5 & -10 & & \\
\hline 7 & $\mathbf{M}$ & 41 & 3 & 1 & & 1.5 & $197 / 136$ & $182 / 101$ & $-15 /-35^{*}$ & 82 & 60 & 39 & 51 & 3.07 & 3.07 & +5 & -3 & & + \\
\hline \multirow[t]{2}{*}{8} & \multirow[t]{2}{*}{$\mathbf{F}$} & \multirow[t]{2}{*}{60} & \multirow[t]{2}{*}{2} & 1 & 300 & & $202 / 109$ & $177 / 90$ & $-25^{*} /-19^{*}$ & & & & & & & +17 & -1 & + & \\
\hline & & & & 2 & & 0.8 & $188 / 107$ & $157 / 83$ & $-31^{*} /-24^{*}$ & 51 & 47 & 53 & 63 & $2 \cdot 68$ & $2 \cdot 02$ & 0 & -7 & & \\
\hline 9 & $\mathbf{M}$ & 67 & 1 & 1 & 150 & & $193 / 109$ & $157 / 69$ & $-36 * /-40^{*}$ & & & & & & & +5 & -2 & & \\
\hline 10 & $\mathbf{M}$ & 49 & 3 & 1 & & $1 \cdot 25$ & $192 / 110$ & $167 / 74$ & $-25^{*} /-36^{*}$ & & & & & & & & 0 & + & + \\
\hline 11 & $\mathbf{F}$ & 49 & 3 & 1 & 750 & & $256 / 143$ & $224 / 138$ & $-32 /-5$ & & & & & & & & & + & + \\
\hline 12 & F & 60 & 2 & 1 & & $2 \cdot 0$ & $214 / 111$ & $192 / 92$ & $-22 /-19^{*}$ & 69 & 57 & 35 & 41 & $2 \cdot 41$ & $2 \cdot 42$ & +8 & & + & \\
\hline \multirow[t]{2}{*}{13} & \multirow[t]{2}{*}{ F } & \multirow[t]{2}{*}{57} & \multirow[t]{2}{*}{1} & 1 & 200 & & $179 / 108$ & $183 / 101$ & $+4 /-7$ & & & & & & & 0 & 0 & & \\
\hline & & & & 2 & 600 & & $184 / 103$ & $180 / 109$ & $-4 /+6$ & 61 & 47 & 42 & 50 & $2 \cdot 62$ & $2 \cdot 33$ & 0 & 0 & & \\
\hline \multirow[t]{2}{*}{14} & \multirow[t]{2}{*}{$\mathbf{F}$} & \multirow[t]{2}{*}{49} & \multirow[t]{2}{*}{3} & 1 & 450 & & $201 / 116$ & $179 / 94$ & $-22 /-17^{*}$ & & & & & & & +19 & -7 & + & + \\
\hline & & & & 2 & & 3.0 & $207 / 117$ & $194 / 105$ & $-13 * /-12 *$ & 71 & 61 & 57 & 62 & 4.05 & $3 \cdot 77$ & +5 & -4 & + & \\
\hline 15 & $\mathbf{F}$ & 65 & 2 & 1 & & 1.5 & $185 / 109$ & $157 / 97$ & $-28 * /-12^{*}$ & 76 & 66 & 44 & 46 & 3.35 & 3.07 & 0 & 0 & & \\
\hline 16 & $\mathbf{F}$ & 50 & 2 & 1 & & 1.0 & $220 / 113$ & $202 / 95$ & $-18 /-18$ & 73 & 64 & 45 & 54 & 3.07 & $3 \cdot 58$ & 0 & -6 & & \\
\hline \multirow[t]{2}{*}{17} & \multirow[t]{2}{*}{$\mathbf{M}$} & 48 & 1 & 1 & 750 & & $156 / 115$ & $138 / 100$ & $-18 * /-15^{*}$ & & & & & & & - & - & & \\
\hline & & & & 2 & & 6.0 & $153 / 108$ & $130 / 88$ & $-23^{*} /-20^{*}$ & 67 & 57 & 54 & 54 & 3.59 & 3.09 & 0 & 0 & & \\
\hline 18 & $F$ & 55 & 2 & 1 & & 0.8 & $204 / 118$ & $191 / 100$ & $-13 /-18^{*}$ & & & & & & & - & - & & \\
\hline 19 & $\bar{F}$ & $\overline{44}$ & 3 & 1 & 750 & & 149 & $\overline{190 / 111}$ & $-49^{*} /-38^{*}$ & 76 & 62 & 51 & 47 & 3.92 & $2 \cdot 90$ & & & & \\
\hline
\end{tabular}

${ }^{*} \mathrm{P}<0.0511^{* *}$ Total daily dose in $\mathrm{mg} .{ }^{* * *} 1=$ Severe; $2=$ Moderate; $3=$ Mild. H.R.-Heart rate. S.V. $=$ Stroke volume in mils. C.O. $=$ Cardiac output in litres $/ \mathrm{min}$. 
Table I, however, the cardiac output was substantially unchanged in all but two trials, in which a fall occurred. Increased cardiac output therefore was not the cause of heart failure.

An explanation, however, which merits consideration is that rauwolfia may have caused in some cases a fluid retention that was capable of precipitating heart failure in those subjects with incipient decompensation. This hypothesis would be consistent with the reported antidiuretic effect of reserpine in animals (Gaunt et al., 1954) and would explain the significant weight gain observed in the absence of failure by other workers and in our Cases 5, 6, and 9. Whatever its cause, the occurrence of failure in 6 of our 19 cases while receiving rauwolfia is an observation of some significance. It suggests that this drug, at least in the presence of a damaged myocardium, should be given with caution, and that an increase in weight and signs and symptoms of failure should be looked for with special care in these subjects.

\section{Summary AND CONClusions}

An extract of the whole root of Rauwolfia serpentina or the alkaloid reserpine were capable of producing a substantial fall in the blood pressure in 16 of 19 subjects with essential hypertension.

The pressure was reduced to normal or near normal levels in 10 of the 19 subjects.

The optimal dose varied from 0.75 to $6.0 \mathrm{mg}$. serpasil and $150-800 \mathrm{mg}$. raudixin daily. Any attempt to lay down a dosage within narrower limits would lead to under treatment in some cases and gross toxicity in others.

The side effects are briefly discussed. In most subjects there was a significant increase in weight and in six subjects temporary heart failure developed while on the drug.

It is suggested that rauwolfia drugs may have an anti-diuretic effect in man which may cause an increase in weight due to fluid retention. Congestive cardiac failure may be precipitated in those with previously damaged hearts.

Whatever the actual mechanism of failure, it is clearly a possible hazard in subjects of poor cardiac status who are treated with rauwolfia drugs. Rauwolfia treatment in these subjects should be undertaken with some caution.

The authors are greatly indebted to Dr. B. van Lingen for his helpful suggestions regarding the planning of this study and the preparation of this paper. They also wish to express their gratitude to Dr. M. M. Zion who assisted them in some of the earlier trials, to Dr. J. Hoffman for statistical help, to Miss M. L. Lister and Miss J. Robinson for carrying out some of the ballistocardiographic recordings and to Professor G. A. Elliott, in whose department this work was carried out, for his encouragement and help.

\section{REFERENCES}

Arnold, O. H., and Bock, K. D. (1953). Dtsch. med. Wschr., 78, 565 and 879.

Chakravarty, N. K., Rai Chaudhuri, M. N., and Chaudhuri, R. N. (1951). Ind. med. Gaz., 86, 348.

Chopra, R. N. (1933). Indigenous Drugs of India. Calcutta.

-, Gupta, J. C., and Mukherjee, B. (1953). Indian J. Med. Research, 21, 261.

Douthwaite, A. H. (1954). Lancet, 266, 1345.

Freis, E. D., and Ari, R. (1954). Ann. N.Y. Acad. Sci., 59, 45.

Gaunt, R., Renzi, A. A., Antonchak, M., Miller, G. J., and Gilman, M. (1954). Ann. N.Y. Acad. Sci., $59,22$.

Hensler, L. (1953). Schweiz. med. Wschr., 83, 1162.

Hughes, W., Dennis, E., McConn, R., Ford, R., and Moyer, J. H. (1954). Amer. J. med. Sci., $228,21$.

Joiner, C., and Kauntze, R. (1954). Lancet, 166, 1097.

Löffler, Von W., Esselier, A. F., Frött, F., and Wegmann, A. (1953). Schweiz. med. Wschr., 83, 1012.

Moyer, J. H. (1954). Ann. N.Y. Acad. Sci., 59, 82.

, Hughes, W., and Huggins, R. (1954). Amer. J. med. Sci., 227, 640.

Sellers, A. M., and Haf kenschiel, J. H. (1954). Amer. J. med. Sci., 228, 114.

Starr, I., Rawson, A. J., Schroeder, H. A., and Joseph, N. R. (1939). Amer. J. Physiol., $127,1$.

Tanner, J. M. (1949). J. clin. Invest., 28, 567.

Vakil, R. J. (1953). J. Ind. med. Ass., 23, 97.

Wilkins, R. W. (1954). Ann. N.Y. Acad. Sci., 59, 36.

, and Judson, W. E. (1953). New Eng. J. Med., 248, 48.

Winsor, T. (1953). Arizona Med., 10, 419.

(1954). Ann. N.Y. Acad. Sci., 59, 61 .

Yule, G. U., and Kendail, M. G. (1940). An Introduction to the Theory of Statistics. C. Griffin \& Co., Ltd., London. 